\title{
SISTEM INFORMASI MANAJEMEN INSTALASI GAWAT DARURAT BP-RB PKU MUHAMMADIYAH PAKEM, SLEMAN, YOGYAKARTA
}

\author{
Yunita Wisda Tumarta Arif, S. Kom., M. Kom \\ Fakultas Ilmu Kesehatan, Universitas Duta Bangsa \\ email: yunita_wisda@udb.ac.id
}

\begin{abstract}
BP-RB PKU Muhammadiyah Pakem is a medical center that is still relatively new and is seriously preparing hardware, software, and brain devices, especially in Emergency Installation (IGD). Patients who come to the emergency room need fast and appropriate assistance. At BP-RB PKU Muhammadiyah Pakem there is a patient registration process, medical records and calculation of payments still made manually so patients must wait for inspection or payment. This makes searching medical records and visiting data examining previous patients longer because they have to look for lines and sheets. The purpose of this study is to establish an Emergency Management Information System that can help health practitioners in the management process in the emergency unit to be faster and easier in finding patient medical records for previous visits and recording patients' medical records so that patients can be treated quickly and accurately . This study uses several steps including: Defining the main problem, Collecting data, Developing information systems, Defining the main problem, Collecting data, Developing information systems. Methods in system development include software requirements analysis, design, implementation, development. The method for building a web-based system using PHP (Hypertext Prepocessor) and database management systems with My SQL.

Keywords: System, Manajemen, IGD
\end{abstract}

\section{PENDAhuluan}

Sistem informasi Manajemen dapat didefinisikan sebagai sekumpulan sub sistem yang saling berhubungan, berkumpul bersama - sama dan membentuk satu kesatuan, saling berinteraksi dan bekerja sama antara bagian satu dengan yang lainnya dengan cara - cara tertentu untuk melakukan fungsi pengolahan data, menerima masukan (input) berupa datadata, kemudian mengolahnya (processing), dan menghasilkan keluaran (output) berupa informasi sebagai dasar bagi pengambilan keputusan yang berguna dan mempunyai nilai nyata yang dapat di rasakan akibatnya baik pada saat itu juga maupun di masa mendatang, mendukung kegiatan operasional, manajerial, dan strategis organisasi, dengan memanfaatkan berbagai sumber daya yang ada dan tersedia sebagai fungsi tersebut guna mencapai tujuan.(Sutanto,2003).

BP-RB PKU Muhammadiyah Pakem merupakan salah satu institusi pelayanan umum yang memiliki kompleksitas yang cukup baik, dari segi ketenagaan, pelayanan, peralatan dan lain-lain.Salah satu unit yang memerlukan sistem informasi manajemen yang cepat dan akurat adalah Instalasi Gawat Darurat (IGD). IGD (Instalasi Gawat Darurat) adalah ujung tombak atau etalase dari suatu media pelayanan kesehatan dimana pasienpasien yang datang dalam kondisi yang terancam nyawanya atau dalam keadaan darurat memerlukan pertolongan yang cepat dan tepat hanya 5 menit setelah sampai di IGD (Mathar:2018). Sehingga dibutuhkan manajemen IGD yang baik agar lebih cepat dan tepat dalam menangani pasien dan mengolah data pasien. BP-RB PKU Muhammadiyah Pakem merupakan balai pengobatan yang masih baru berdiri, dalam manajemen data pasien hingga pembayaran masih manual dengan tulis tangan. Ada 1 komputer di sana yang digunakan untuk merekap data pasien saja.

Dengan banyaknya pasien IGD maka semakin banyak data pasien yang harus diproses dan disimpan, termasuk rekam medis 
pasien. Sistem Teknologi Informasi memberikan banyak peran dalam organisasi, salah satu peran utama adalah efisien dan efektivitas (Kasemin:2015). Efektivitas dapat dicapai salah satunya dengan Sistem Informasi Manajemen (SIM). Untuk membantu praktisi kesehatan di BP-RB PKU Muhammadiyah Pakem dalam manajemen IGD agar peran IGD menjadi lebih baik dan lebih maksimal dibutuhkan sebuah sistem informasi manajemen IGD dalam pemrosesan data agar manajemen IGD di BP-RB PKU Muhammadiyah Pakem masih kurang efektif karena kurangnya sistem teknologi informasi yang mendukung bisa teratasi. Dari latar belakang tersebut penulis termotifasi untuk membuat sistem informasi manajemen IGD BP-RB PKU Muhammadiyah Pakem berbasis web. Kecepatan dalam mengakses, penambahan informasi dan proses pembaharuan sistem dapat dilakukan setiap saat sehingga dapat meningkatkan kinerja.

Sistem yang akan dibangun berbasis webste dengan menggunakan aplikasi Dreamweafer dalam proses pembuatannya. Metode pembangunnan sistem dengan enggunakan PHP(Hypertext Prepocessor) dan sistem basis data menggunakan My SQL. Sistem berbasis web juga tidak perlu instalasi seperti aplikasi lian karena server ada berada pada satu tempat dan cukup menggunakan browser untuk menggunakan system (Solichin:2016).

\section{METODE PENELITIAN}

Perancangan dan pembangunan sistem informasi IGD memerlukan beberapa metode penelitian, metode penelitian yang digunakan dalam penelitian ini adalah:

1. Mendefinisikan masalah utama dan menetapkan tujuan pokok permasalahan dalam penelitian ini sudah dijelaskan sebelumnya di rumusan masalah dan tujuan penelitian.

2. Mengumpulkan data yang diperlukan menggunakan beberapa metode, yaitu :

a. Observasi, Observasi di lakukan dengan cara pengamatan secara langsung proses-proses pada manajemen IGD BP-RB PKU Muhammadiyah Pakem. b. Wawancara, dengan wawancara halhal yang tidak diketahui dilapangan dapat ditanyakan secara langsung kepada pihak yang bersangkutan.

c. Studi pustaka, Penelusuran dan pengumpulan data-data yang dibutuhkan yang berasal dari buku, makalah dan artikel yang berhubungan dengan IGD.

3. Pengembangan sistem informasi ini mempunyai 4 tahap, yaitu :

a. Analisis kebutuhan perangkat lunak, untuk pendefinisian ruang lingkup, kebutuhan sistem dan antar muka (interface) yang dibutuhkan.

b. Desain, untuk penetuan arsitektur perangkat lunak beserta antar muka (interface), struktur data dan detail fungsional.

c. Implementasi, merupakan tahap penerapan dari hasil analisidan desain menjadi perangkat lunak yang dapat difungsikan sesuai dengan tujuan pengembangan.

d. Pengembangan, untuk melakukan verifikasi dan validasi terhadap perangkat lunak yang dihasilkan.

\section{HASIL DAN PEMBAHASAN}

\subsection{Analisis Proses Bisnis}

Analisis proses bisnis merupakan analisis proses yang ada di IGD BP-RB PKU Muhammadiyah Pakem. Proses dari pasien datang sampai pasien selesai kunjungan. Adapun proses seperti gambar 1 Analisis proses bisnis sebagai berikut: 


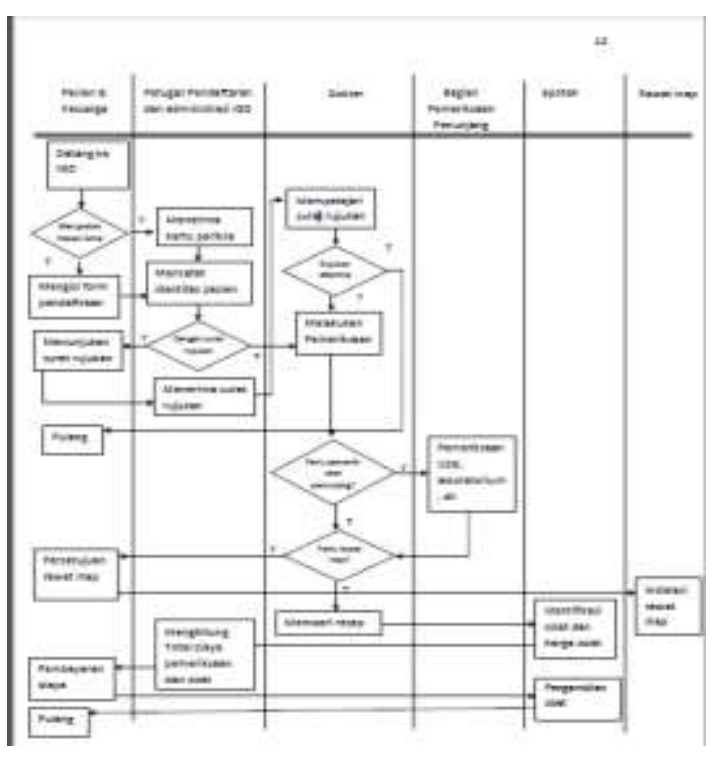

Gambar I. Proses Bisnis Sistem

Dari proses bisnis pada gambar 1 terdapat kemungkinan permasalahan yang akan dihadapi adalah :

1. Sangat memungkinkan terjadi duplikasi nomor rekam medis pasien, sehingga satu pasien bisa mempunyai lebih dari satu nomor rekam medis.

2. Proses pelayanan yang terlalu lama dapat membuat pasien mengalami kekecewaan.

3. Banyaknya penggunaan kertas membuat rumit dalam pencarian dan membutuhkan waktu yang cukup lama untuk menemukan data pasien, selain itu data juga mudah hilang dan terselip.

\subsection{Perancangna use case diagram}

Usecase diagram merupakan sebuah diagram yang menggambarkan alur proses dari sebuah sistem dari aktor yang mewakili pengguna sistem hingga proses yang dapat di lakukan pengguna dari sistem tersebut. Usecase diagram dapat digunakan selama proses analisis untuk menangkap requirement sistem dan untuk memahami proses apa saja yang diperbuat oleh sistem. Untuk usecase diagram pada Sistem Informasi Manajemen BP-RB PKU Muhammadiyah Pakem dapat dilihat pada gambar 2 .

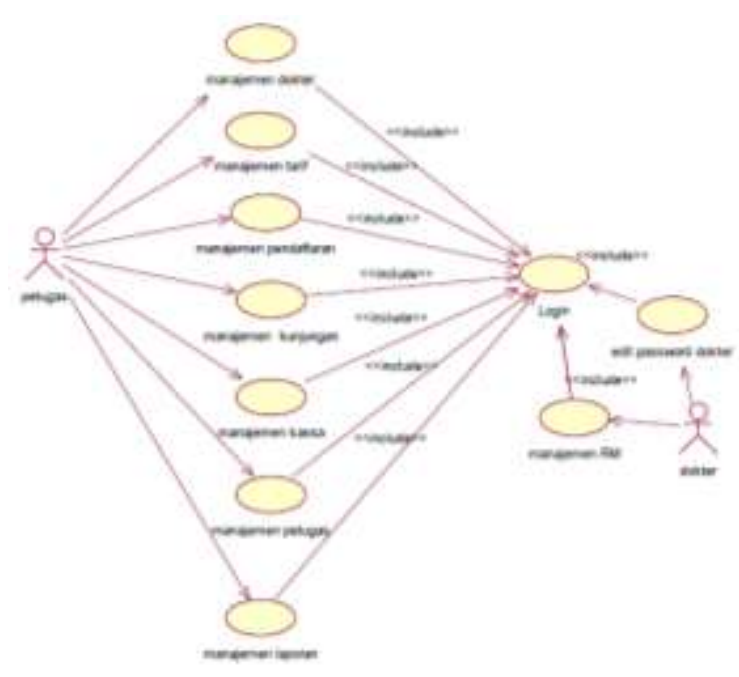

Gambar 2 Usecase Diagram

Dari gambar 2 usecase diagram dapat diketahui pengguna yang dapat login kedalam sistem adalah dokter dan petugas IGD. Setiap pengguna mempuyai hak akses masing masing dalam menggunakan sistem.

Pengguna dokter dapat login, merubah password dan menambahkan rekam medis pasien. Pengguna petugas dapat login , melakukan manajemen dokter, manajemen tarif, manajemen pendaftaran, manajemen kunjungan, manajemen kassa, manajemen petugas dan manajemen laporan.

\subsection{Perancangan basis data}

Rancangan basis data untuk pembangunan Sistem Informasi Manajemen BP-RB PKU Muhammadiyah Pakem seperti gambar 3 rancangan basis data:

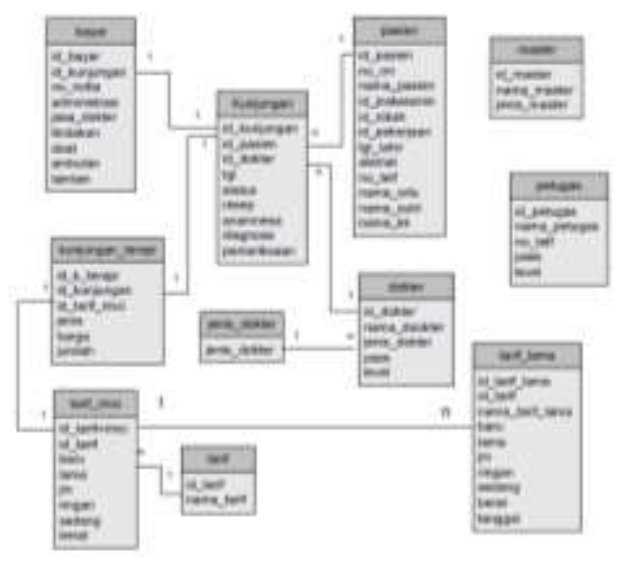

Gambar 3 Rancangan Basis Data 


\subsection{Antarmuka sistem}

Antarmuka antara sistem dengan pengguna sangatlah penting. Sebuah sistem yang mempunyai antar muka yang menarik belum tentu pengguna bisa dan mudah mengoperasikannya. Sistem ini merupakan sistem yang di rancang dengan sederhana dan mempunyai antar muka yang mudah dioperasikan oleh pengguna. Berikut adalah implementasi antarmuka dari Sistem Informasi Manajemen IGD BP-RB PKU Muhammadiyah Pakem :

1. Antarmuka halaman login
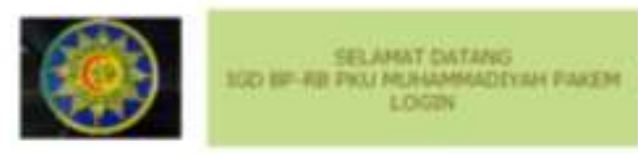

Benopura

Fasmeord

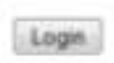

Gambar 4 halaman login

2. Antarmuka halaman dokter

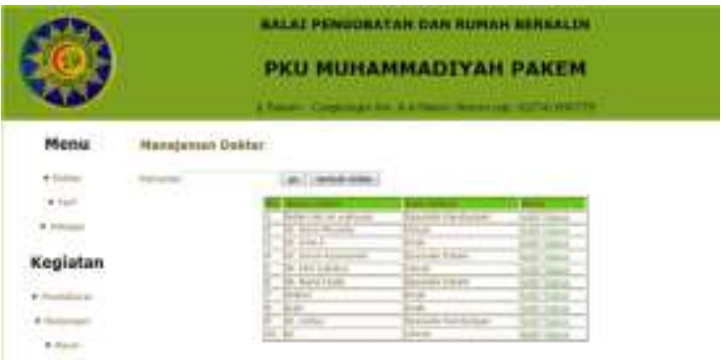

Gambar 5 halaman dokter

3. Antarmuka halaman pendaftaran



Gambar 6 halaman pendaftaran

4. Antarmuka halaman input data pasien

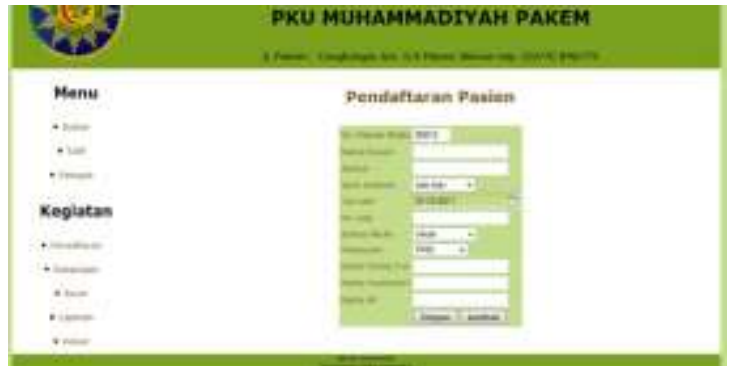

Gambar 7 halaman input data pasien

5. Antarmuka halaman input rekam medis

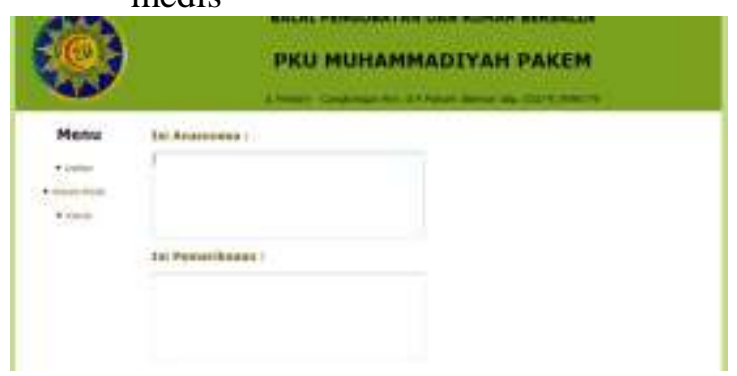

Gambar 8 halaman input rekam medis

6. Antarmuka halaman tagihan bayar



Gambar 9 halaman tagihan bayar

\section{KESIMPULAN}

Dari hasil penelitian tentang Sistem Informasi Manajemen IGD BP-RB PKU Muhammadiyah Pakem, dapat diambil beberapa kesimpulan sebagai berikut:

1. Sistem Informasi Manajemen Instalasi Gawat Darurat (IGD) merupakan sistem informasi yang dibuat guna membantu dalam manajemen IGD di BP-RB PKU Muhammadiyah Pakem Sleman.

2. Pencarian rekam medis pasien disetiap kunjungan dapat di lakukan dengan mudah dan cepat, sehingga pasien tidak terlalu lama menunggu dan dokter dapat segera mempelajari riwayat pasien dan menangani pasien dengan cepat.

3. Pada Sistem Informasi Ini juga terdapat manajemen keuangan pada tarif. Tarif dapat dimanipulasi sewaktu-waktu ada penambahan atau perubahan tarif dari 
semua tindakan, namun terdapat juga menu history yang merekap semua perubahan yang terjadi pada tarif. Menu history ini sangat berguna bagi petugas karena dengan menu history petugas dapat mengetahui setiap ada perubahan tarif sebagai pengamanan jika ada perubahan data karena manajemen keuangan sangatlah riskan dan berpengaruh dengan pembayaran pasien.

\section{REFERENSI}

Kasemin, Kasiyanto. Drs. H. M. Si., APU. Agresi Perkembangan Teknologi Informasi. Jakarta

Mathar. Irmawti. 2018. Manajemen informasi kesehatan pengelolaan rekam medis. Budi Utama. Yogyakarta.

Sutanto, Edhy. 2003. Sistem Informasi Manajemen. Graha Ilmu. Yogyakarta

Solichin. Ahmad. 2016. Pemrograman Web dengan PHP dan My SQL. Budi luhur. Jakarta 